\title{
Properties of flat-pressed wood plastic composites as a function of particle size and mixing ratio
}

\author{
Khandkar- Siddikur Rahman ${ }^{1} \cdot$ Md Nazrul Islam $^{1}$ · Sourav Bagchi Ratul ${ }^{1}$. Nabila Hasan Dana ${ }^{1}$. Saleh Md. Musa ${ }^{1}$. \\ Md. Obaidullah Hannan ${ }^{1}$
}

Received: 22 September 2017 / Accepted: 14 January 2018 / Published online: 14 February 2018

(c) The Japan Wood Research Society 2018

\begin{abstract}
This paper presents the effects of particle size and mixing ratio on the properties including physical, mechanical, and decay resistance of wood plastic composites (WPCs). In addition, it also presents the effects of immersion temperatures on water absorption (WA) and thickness swelling (TS) of the WPCs. WPCs with a thickness of $6 \mathrm{~mm}$ were fabricated from Albizia richardiana King \& Prain wood particles and recycled polyethylene terephthalate (PET) by the flat-press method. To prepare the WPCs, two different wood particle sizes $(0.5-1.0$ and 1.01-2.0 mm) were used along with four different mixing ratios $(w / w)$. Subsequently, the physical properties include density, moisture content, WA, and TS, and mechanical properties include modulus of elasticity (MOE) and modulus of rupture (MOR) of the produced WPCs was evaluated. Furthermore, decay resistance was evaluated by the weight loss percentage method. Moreover, the effects of immersion temperatures on WA and TS of WPCs after $24 \mathrm{~h}$ of immersion in water at three different temperatures, i.e., 25,50 , and $75^{\circ} \mathrm{C}$ were investigated. Results showed that the wood particle size had impact on WPC's density (only 6\% decreased with the increase of particle size); however, the density decreased by $29 \%$ when the wood particle content increased from 40 to $70 \%$. The WA and TS gradually increased with the increase of particle content and decrease of particle size. In addition, WA and TS increased proportionately with increasing immersion temperature from 25 to $75^{\circ} \mathrm{C}$. Furthermore, the highest MOE $\left(2570 \mathrm{~N} / \mathrm{mm}^{2}\right)$ was found for the WPCs fabricated from large wood particles having the ration of 50:50 (wood particle:PET). For decay resistance, WPCs consisted of larger particles and higher PET content showed greater resistance against decay. Therefore, it is comprehensible that fabrication of the WPCs from 50\% large particles and 50\% PET is technically feasible and further improvement of WPC performance like enhancement of MOE and reduction of density using coupling agent and agricultural waste fibers, respectively, in the WPC formulation is recommended.
\end{abstract}

Keywords Albizia richardiana $\cdot$ PET $\cdot$ Hot pressing $\cdot$ Physical and mechanical properties $\cdot$ Decay resistance

\section{Introduction}

Wood plastic composites (WPCs) are comparatively new generation of composite materials, which is a first growing and auspicious sector of both wood composite and plastic industries worldwide. It comprises a combination of wood (in various forms) and thermoplastic materials under heat and pressure [1]. In addition, the WPC matrix may contain additives that improve the quality of WPCs. Usually, virgin plastics are used for the fabrication of the WPCs.

Khandkar- Siddikur Rahman

rana_ksr@yahoo.com

1 Forestry and Wood Technology Discipline, Life Science School, Khulna University, Khulna 9208, Bangladesh
However, recently, recycled plastics have gained attention to the researchers for the WPC fabrication [2,3]. Recycled plastics that can be processed below the degradation temperature $\left(200{ }^{\circ} \mathrm{C}\right)$ of wood are suitable for producing WPCs with emerging technologies [3, 4].

Predominant technologies to fabricate WPCs are the extrusion and injection molding that are commercially less important [5]. Because manufacturing of WPCs with large-sized particles seems difficult with extrusion process due to its high machinery expense [6] and only three-dimensional forms are prepared by following injection molding [5]. Hence, to overcome all these problems, the flat-press method has been developed for fabrication of the WPCs [7, 8]. Fabrication of WPCs with the flat-press method in laboratory resembles to the standard procedure of composites production in industry. Compared 
to the extrusion and injection molding, higher productivity and lower pressing pressure requirement are the advantages of flat-press method. WPCs manufactured by following this method have larger dimension [9]. This process also ensures the low density of WPCs having the natural wood structure $[8,9]$. Accordingly, along with the virgin materials, recycled materials including plastic and wood have significant potential for fabrication of WPCs with flat-press method [9]. Hence, many researches have been conducted on WPC fabrication with different mixing ratios of wood particles and thermoplastics using the flat-press method [3-12].

Rahman et al. [3] investigated the feasibility of recycled polyethylene terephthalate (PET) and sawdust as raw materials for WPC fabrication by flat-press method, where sawdust and PET were used as reinforcing material and binding agent, respectively. PET in the form of bottles and containers of food is abundant, because packaging industries used PET intensively. Recycling of PET offers a potential solution for preventing environmental pollution and scope for manufacturing of WPCs. The effects of different mixing ratios of sawdust and PET on the physical and mechanical properties of WPCs was only considered for the study [3]. However, the effect of different particle sizes on WPCs containing wood particles and PET has not been studied yet. In an earlier research, Chen et al. [6] reported that the large size wood particles increased the bending strength and decreased the density of composites. In the meantime, natural decay resistance or durability is another important issue for the WPCs performance and recent concerns about it is increasing [13], because wood particles or fibers are biodegradable [13] and hygroscopic [2] in nature that exposed to extreme conditions. However, Rahman et al. [3] did not report the decay resistance of the WPCs in the earlier research. In addition, WPCs are designed for external use, where water absorption (WA) and varying exposure temperature are crucial factors affecting WPC performance [2]. Najafi et al. [2] reported that immersion temperature has negative effects on the WA of WPCs, and WA is one of the determining factors for the application of WPCs. Accordingly, research on the decay resistance and effect of immersion temperature on WA of WPCs containing wood particle and PET is imperative. Therefore, this study was designed to assess the effects of different mixing ratios and particle sizes on the physical and mechanical properties along with decay resistance of WPCs. Moreover, the effects of immersion temperatures on WA and thickness swelling (TS) of the WPCs were also studied.

\section{Materials and methods}

\section{Preparation of raw materials}

A freshly felled Raj koroi log (Albizia richardiana King \& Prain) having $30 \mathrm{~cm}$ diameter and $14 \mathrm{~m}$ height was collected
Table 1 Formulations of wood-polyethylene terephthalate (PET) composites

\begin{tabular}{lll}
\hline Formulation & \multicolumn{2}{l}{ WPC composition based on weight \% } \\
\cline { 2 - 3 } & Particle content (\%) & $\begin{array}{l}\text { PET } \\
\text { content } \\
(\%)\end{array}$ \\
\hline A-40 & 40 & 60 \\
A-50 & 50 & 50 \\
A-60 & 60 & 40 \\
A-70 & 70 & 30 \\
B-40 & 40 & 60 \\
B-50 & 50 & 50 \\
B-60 & 60 & 40 \\
B-70 & 70 & 30 \\
\hline
\end{tabular}

$W P C$ wood plastic composite, $A$ WPC from small particles, $B$ WPC from large particles

from Khulna, Bangladesh. The log was debarked and converted into wood chips using a traditional sharp hand-cutting tool. Afterwards, a laboratory scale grinder was used to convert the wood chips into particles. The particles were screened to remove smaller $(<0.5 \mathrm{~mm})$ with mesh no. 35 and oversized $(>2 \mathrm{~mm})$ particles with mesh no. 10. Subsequently, the particles were classified into small particle (A) and large particle (B) screening through mesh no. 18. The size of small and large particles was 0.5-1.0 (mesh no. 35 and 18) and 1.01-2.0 mm (mesh no. 18 and 10), respectively, according to ASTM E11-17 standard [14]. Consequently, wood particles were dried in a laboratory oven for $24 \mathrm{~h}$ at $103 \pm 2{ }^{\circ} \mathrm{C}$ for reducing the moisture content to $2 \%$. Besides, the post-consumer drinking water bottles (plastic grade 1) were collected locally and cleaned. A rotary grinder was used to produce PET powder. Then, PET powder was passed through a 60 mesh size sieve to remove the oversized particles. Afterwards, PET powder was dried at $103 \pm 2{ }^{\circ} \mathrm{C}$ for $24 \mathrm{~h}$ to a moisture content of $3 \%$ or less with a laboratory oven. Density, melt flow index, and melting point of recycled PET were $1370 \mathrm{~kg} / \mathrm{m}^{3}, 18.4 \mathrm{~g} / 10 \mathrm{~min}$, and $260^{\circ} \mathrm{C}$, respectively.

\section{Flat-pressed WPCs manufacturing}

Small (A)- and large (B)-sized particles were mixed separately with PET powder for 6 min in a rotary-type blender for producing a homogeneous composite by following the formulation, as illustrated in Table 1. Uniform mats were formed by placing the mixture on an aluminium caul plate using a forming box. The WPCs were fabricated according to the press cycle reported by Chen et al. [6]. The press cycle of this study involves maximum pressing temperature $\left(190{ }^{\circ} \mathrm{C}\right)$, pressure $\left(5 \mathrm{~N} / \mathrm{mm}^{2}\right)$, pressing time $(5 \mathrm{~min})$, and pressure holding time, i.e., cold pressing (6 min). To 
avoid the degradation of wood components, pressing temperature $\left(190^{\circ} \mathrm{C}\right)$ was set below the melting temperature $\left(260{ }^{\circ} \mathrm{C}\right)$ of PET [3]. Six replications of each type of WPC panels with $300 \times 250 \times 6 \mathrm{~mm}$ dimension were fabricated. The WPC panels were trimmed and conditioned at room temperature for $48 \mathrm{~h}$ before testing.

\section{Evaluation of composite properties}

To evaluate the physical and mechanical properties of each type of WPCs, all specimens were carefully prepared and tested according to the ASTM D1037 standard [15]. Moreover, the decay resistance test was done by following soil block test according to BS EN ISO 846: 1997 standard [16]. For each type of WPC, at least six specimens were used to evaluate each property. A total of 336 specimens from six replications of each type of WPC were used to evaluate the properties including physical properties, mechanical properties, and biological decay resistance of the WPCs. The physical properties include density, moisture content, WA, and TS; and the mechanical properties include modulus of elasticity (MOE) and modulus of rupture (MOR). The room temperature and relative humidity during the tests were $23 \pm 2{ }^{\circ} \mathrm{C}$ and $65 \pm 2 \%$, respectively. The properties of the WPCs were compared with the ANSI standard [17] for wood-based panels, as there was no WPC panel standard for comparison [10].

\section{Physical properties}

Physical properties were measured with the specimens that have the dimension $50 \times 50 \times 6 \mathrm{~mm}$. Among the physical properties, density of the WPCs was measured by following the ASTM D1037 standard [15]. Moisture content of WPC specimens was measured with an oven dry method [15], while the temperature was $103 \pm 2{ }^{\circ} \mathrm{C}$ for $24 \mathrm{~h}$. Moreover, in this study, WPC specimens were immersed in water for $24 \mathrm{~h}$ at 25 (room temperature), 50 and $75^{\circ} \mathrm{C}$, to measure the WA and TS according to Najafi et al. [2]. The WA and TS of the specimens were calculated as percentages.

\section{Mechanical properties}

MOE and MOR of the WPC specimens were measured by following the three point bending test with a universal testing machine (Model IB600, IMAL, Italy) according to the ASTM D1037 standard [15]. To determine the MOE and MOR, WPC panels were cut into rectangular sections having the dimension $240 \times 50 \times 6 \mathrm{~mm}$.

\section{Decay resistance}

Weight loss is considered as an indicator of natural decay of the WPCs that was evaluated by soil burial test in a glass box $(100 \times 60 \times 55 \mathrm{~cm})$ according to BS EN ISO 846 standard [16]. Eight different glass boxes were used for eight types of samples. The dimension of the WPC specimens was $20 \times 20 \times 6 \mathrm{~mm}$. Containers were filled with natural soil having 50\% moisture content and 90\% moisture holding capacity. The moisture holding capacity of the soil was calculated by the oven dry method of the moisture content determination. The specimens were placed in permanent contact of the soil for 12 weeks at room temperature $\left(23 \pm 2{ }^{\circ} \mathrm{C}\right)$. Six specimens of each type of WPC were planted vertically into the soil, maintaining a fixed distance of $3 \mathrm{~cm}$ from each other. Activities of the soil microorganisms were monitored clearly using Shirley cotton stripes. After 12 weeks, weight loss percentage of the WPC specimens was calculated using the oven dry method.

\section{Statistical analysis}

Analysis of data was carried out with the SPSS software (version 16.0) at the 95\% confidence level. To determine the effects of particle size and mixing ratio on density, moisture content, MOE, MOR, and decay resistance, two-way analysis of variance (ANOVA) followed by least significant difference (LSD) test was carried out. Furthermore, the effects of particle size, ratio, and immersion temperature on WA and TS of the WPCs was analyzed with the analysis of covariance (ANCOVA), where particle size and ratios were the factors and immersion temperature was covariate.

\section{Results and discussion}

\section{Physical properties}

Two-way ANOVA followed by LSD showed significant effect of particle sizes $\left(F_{1,40}=568.868, P<0.05\right)$ and mixing ratios $\left(F_{3,40}=1.640 \times 10^{3}, P<0.05\right)$ on the density of the WPCs. The density of WPCs from small and large particles ranged from 849 to 1100 and 801 to $1047 \mathrm{~kg} / \mathrm{m}^{3}$, respectively. It was observed that the density for WPCs of both A- and B-type particles decreased with the increased particle content in the formulations from 40 to $70 \%$. Moreover, A-40-type WPCs showed higher density $(1100 \mathrm{~kg} /$ $\mathrm{m}^{3}$ ), while B-70-type WPCs showed the lowest density $\left(801 \mathrm{~kg} / \mathrm{m}^{3}\right)$ compared to the other formulations (Fig. 1). For increased particle content of $40-70 \%$, the density of the WPCs decreased up to around $29 \%$. However, $6 \%$ reduction of density was observed for large size particles compared to small particles. The density variations might be 


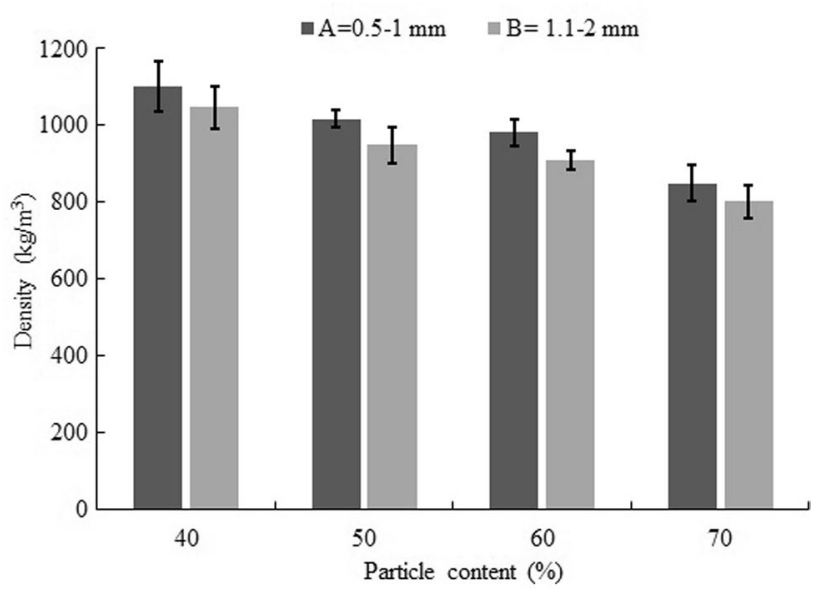

Fig. 1 Effects of wood particle size and mixing ratio on density of Aand B-type WPCs. In figure, error bars indicate the standard error of the mean

the outcome of the both particle size and mixing ratios of particle to PET in the formulations. Higher surface area of fine particles ensures equal spreading of adhesive with high compaction ratio resulting higher density of the WPCs. In addition, smaller particles contain fewer pores and hollow areas, which increase that the WPCs weight eventually contributes to increasing density that might be another cause. Therefore, WPCs from small particles showed higher density than larger particles because of high compaction ratio and lower pores [3] and this result is supported by Chen et al. [6]. The results of this study comply with the results reported by Chen et al. [6] and Rahman et al. [3] regarding the density variation with respect to the mixing ratios. However, the average density of WPCs panels met the requirement of high-density $\left(800 \mathrm{~kg} / \mathrm{m}^{3}\right)$ particleboard according to the ANSI standard [17] that indicate the density of WPCs need to reduce. Thus, to attain medium density of the WPCs, further research is imperative, where agricultural waste fibers along with the higher particle content; the addition of coupling agent in the WPC formulation could be potential solution.

The moisture content of WPCs varied significantly based on particle sizes $\left(F_{1,40}=248.424, P<0.05\right)$ and mixing ratios $\left(F_{3,40}=741.52, P<0.05\right)$ according to the two-way ANOVA followed by LSD. The moisture content of the fabricated WPCs ranged between 0.79 and $2.24 \%$ (Fig. 2). B-70 WPCs showed higher moisture content (2.24\%), while A-70 showed $2.01 \%$ moisture content. On the other hand, A-40type WPCs showed the lowest moisture content among all the composites. Like wood particles, PET is hydrophobic in nature and has a tendency to impede the access of moisture into composites. In addition, rise of moisture content with the augmentation of particle size might be results of the higher number of pore in large particles, which may create

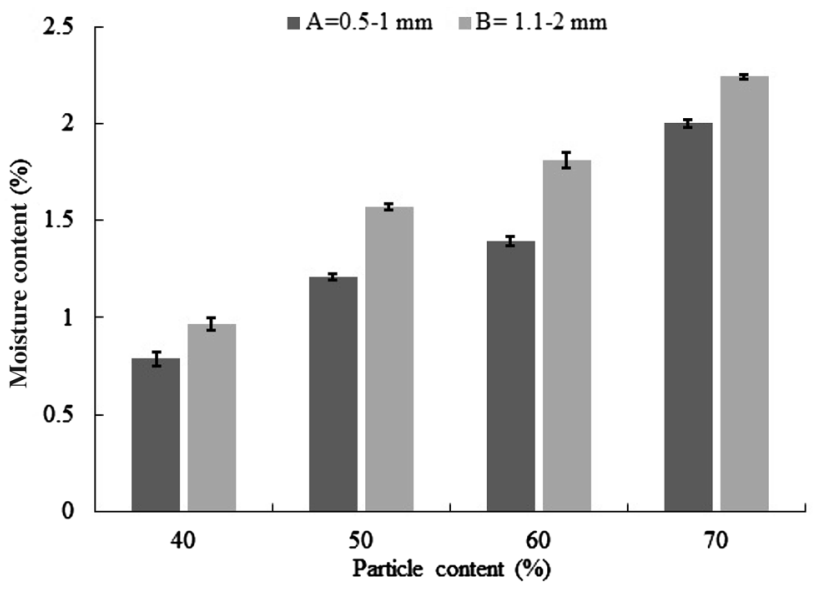

Fig. 2 Effects of wood particle size and mixing ratio on moisture content of A- and B-type WPCs. In figure, error bars indicate the standard error of the mean

openings for moisture movement into composites. Moreover, the increased moisture content of the WPCs is due to the presence of gaps that flaws in the interface and microcracks in the matrix [18]. Later, Rahman et al. [3] reported similar results of moisture content for the WPCs fabricated from sawdust and PET at four different mixing ratios. In addition, the results of this study comply with the research of Chen et al. [6] for the composites made of high-density polyethelene (HDPE) and different size recycled wood particles. Usually, the increasing plastic content in the matrix decreases the moisture content of WPCs. According to ANSI standard [17], the average moisture content of composite should not exceed 10\% (based on oven dry weight). Thus, the moisture content of the composites was substantially lower than that of the required standard and moisture content of the WPCs depend on the plastic content.

Statistical analysis (ANCOVA) of WA considering the particle sizes $\left(F_{1,135}=312.332, P<0.05\right)$, mixing ratios $\left(F_{3,40}=1.987 \times 10^{3}, P<0.05\right)$, and immersion temperatures $\left(F_{1,40}=2.671 \times 10^{3}, P<0.05\right)$ revealed that there was significant difference among the WPCs. Like WA, TS of the WPCs was affected significantly by the particle sizes $\left(F_{1,135}=124.071, P<0.05\right)$, mixing ratios $\left(F_{3,135}=440.463, P<0.05\right)$, and immersion temperatures $\left(F_{1,135}=440.167, P<0.05\right)$. With the increased particle content and immersion temperature, WA and TS increased for WPCs from both A and B size particles. Moreover, 70:30 wood-plastic mixing ratio showed higher WA and TS compared to the other mixing ratios for both- A and B-type composites (Figs. 3, 4). The hydrophilic nature of wood might be responsible for these accredited results. The molecular structure of wood consists of hydroxyl groups, which generally responsible for the affinity to water [1]. These hydroxyl groups increase the potentiality 
Fig. 3 Water absorption of Aand B-type composites at different mixing ratios and immersion temperatures. In figure, error bars indicate the standard error of the mean

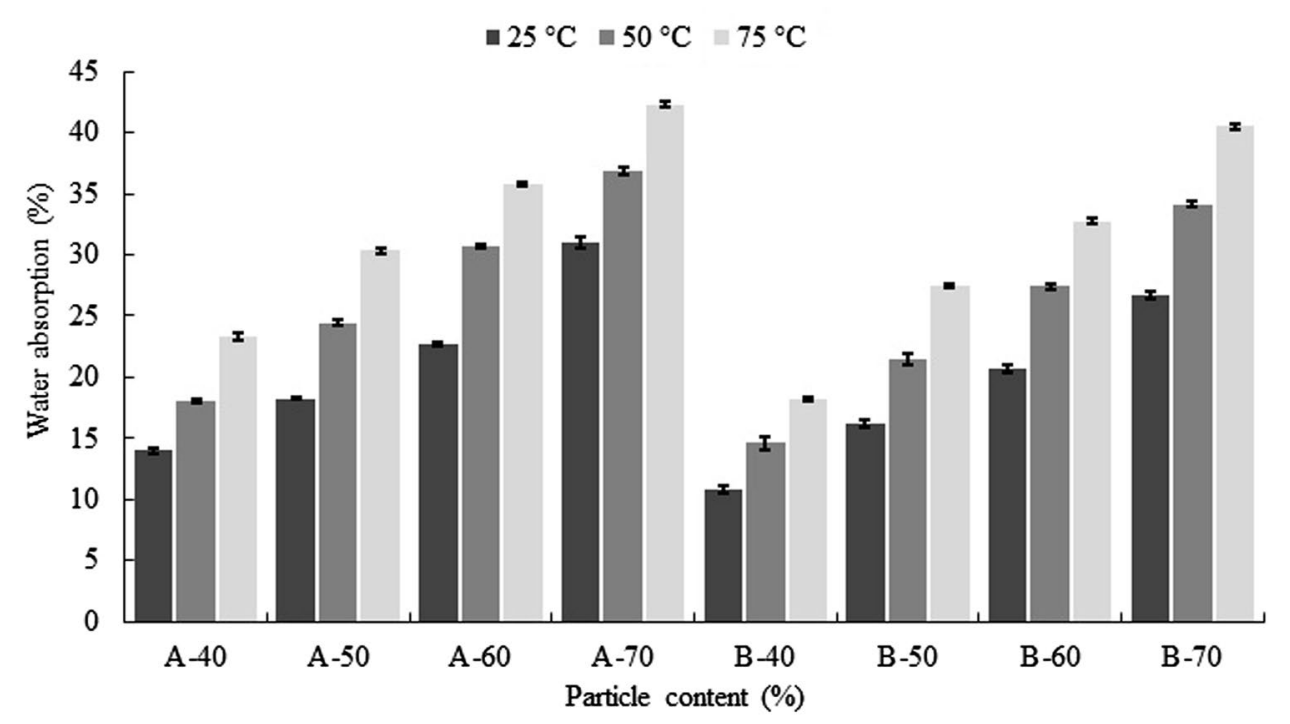

Fig. 4 Thickness swelling of Aand B-type composites at different mixing ratios and immersion temperatures. In figure, error bars indicate the standard error of the mean

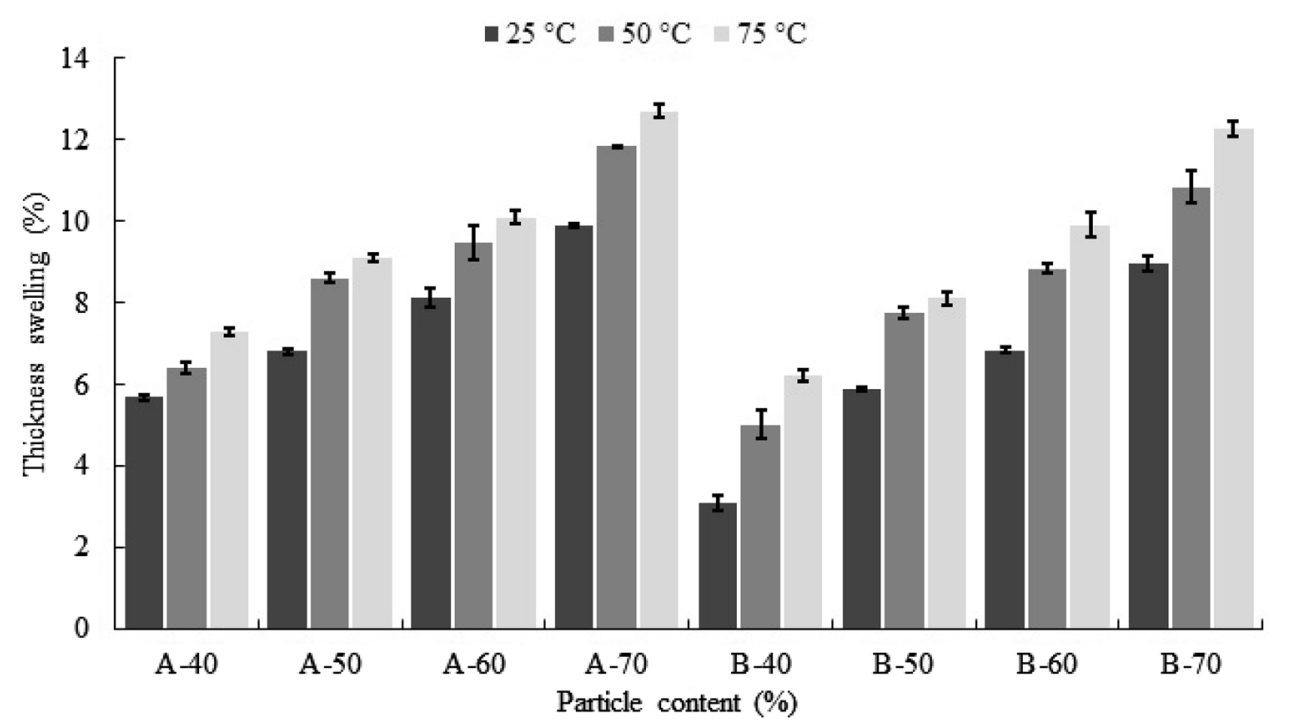

of WA under humid condition of WPCs [18]. Moreover, WPCs made from large particles showed lower WA and TS than the WPCs made of small particles. It was also evident that higher WA results in higher TS of the WPCs (Figs. 3, 4). After $24 \mathrm{~h}$ immersion in water, WPCs contained having large particles showed 4-27\% lower WA than smaller particles. The immersion temperatures also showed a substantial effect on WA and TS of the WPCs. With the increasing temperature from 25 to $75^{\circ} \mathrm{C}$, the WA and TS of composites increased in a higher percentage in this study and that supported by the results of WA with respect to immersion temperature reported in earlier study [2]. Moreover, Ayrilmis et al. [10] reported similar results for the variation in TS of WPCs. In the meantime, Najafi et al. [2] also reported that several other factors like surrounding temperature, plastic type and virginity also have an influence on the WA of WPCs. Therefore, WA and
TS of WPCs depend on the particle size, mixing ratios of wood particle and PET and immersion temperature.

\section{Mechanical properties}

Figure 5 illustrates the effect of particle sizes and mixing ratios on the MOE of the WPCs. Statistical analysis with two-way ANOVA followed by LSD showed significant difference for MOE between the WPCs made from two different particle sizes $\left(F_{1,40}=219.288, P<0.05\right)$ and among the four different mixing ratios $\left(F_{3,40}=1.410 \times 10^{3}, P<0.05\right)$. The increased wood particle content of 40-50\% significantly increased the MOE values of both A and B types of WPCs. Furthermore, the average MOE for the A-50- and B-50-type WPCs was 2329 and $2570 \mathrm{~N} / \mathrm{mm}^{2}$, respectively. The MOE of the WPCs started to decrease with the higher wood particle loading (from 60 to $70 \%$ ) in the formulation (Fig. 5). 


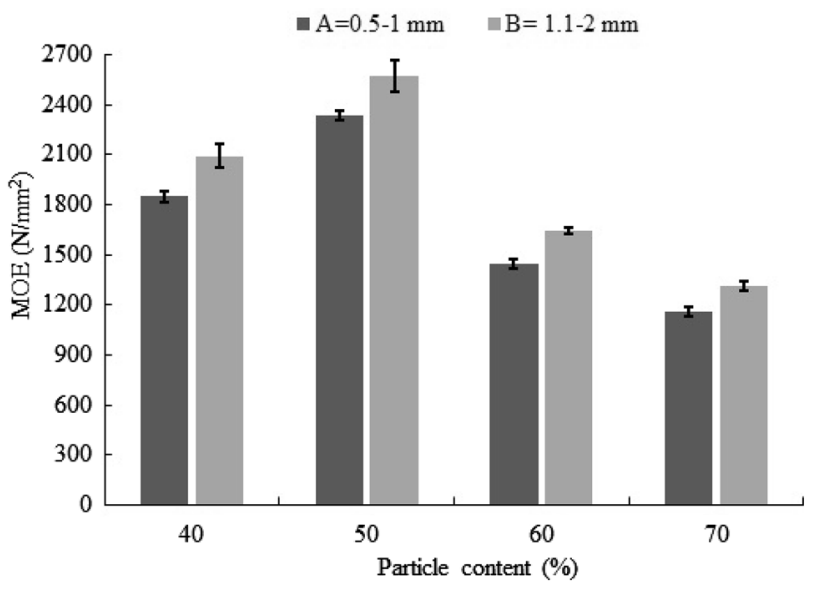

Fig. 5 Effects of particle size and mixing ratio on the MOE of the Aand B-type WPCs. In figure, error bars indicate the standard error of the mean

The poor interfacial interaction between wood and PET due to the lower quantity of PET in the WPC formulation might be the cause of this variation. In addition, higher melting temperature of PET $\left(260^{\circ} \mathrm{C}\right)$ than the pressing temperature $\left(190{ }^{\circ} \mathrm{C}\right)$ of WPCs and thus, thermoplastic might not flow properly within the composites [3] and contributed to a limited scale in bond formation within the WPCs in this study. However, self-bonding mechanisms resulted from the lignocellulosic materials and processing parameters might also contributed in the bond formation among the particles of the WPCs. The self-bonding mechanisms encompass autocrosslinking reactions of lignin, hydrogen bonding between polar carbohydrate components like, cellulose, starch and lignin, and protein denaturation [19]. In the meantime, earlier researcher reported similar results regarding the increasing the particle content above 50\%, reduces adhesive content in the formulation and that leads to inadequate bonding for attaining elevated modulus value [4]. Later, Rahman et al. [3] reported similar results for the WPCs from different mixing ratios of PET and saw dust, and it supported the results of this study. However, WPCs from both small and large particles with 40 and $50 \%$ particle content fulfilled the required standard of ANSI [17] $\left(1725 \mathrm{~N} / \mathrm{mm}^{2}\right)$ for medium density particleboard, while only MOE of the B-50 WPC fulfills the required standard of ANSI [17] for high-density particleboard $\left(2400 \mathrm{~N} / \mathrm{mm}^{2}\right)$. This indicates the need for further research to improve the MOE of the WPCs. Hence, further research with coupling agents might be a solution to improve the MOE of the WPCs with higher particle and lower PET content as the coupling agents facilitate the flow of thermoplastic matrix in the WPCs and enhance the compatibility between wood particles and thermoplastics [20].

Unlike MOE, the MORs of the WPCs were significantly varied, considering the particle sizes $\left(F_{1,40}=2.392 \times 10^{3}\right.$,

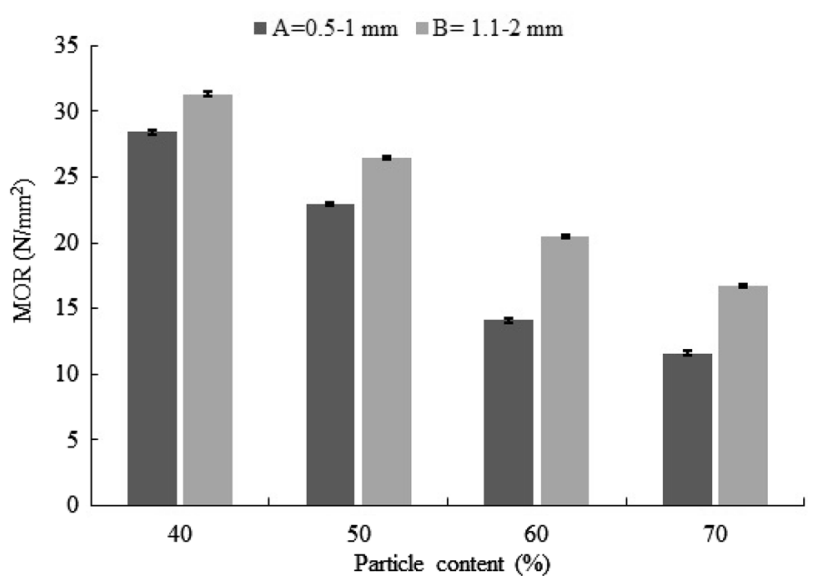

Fig. 6 Effects of particle size and mixing ratio on MOR of the A- and B-type WPCs. In figure, error bars indicate the standard error of the mean

$P<0.05)$ and mixing ratios $\left(F_{3,40}=5.729 \times 10^{3}, P<0.05\right)$ according to the ANOVA and post hoc test LSD. The MOR of A- and B-type WPCs gradually decreased with the increased wood particle content in the formulations from 40 to $70 \%$. Moreover, B-type WPCs made of large particles showed greater MOR than A-type WPCs from small particles (Fig. 6). This may occur due to larger surface area of fine particles than large particle. Thus, the polymeric matrix cannot totally cover the surface area of fine particles that causes the poor interfacial interaction between the particles, and, thus, results in strength loss of composites [21]. Later, Chen et al. [6] reported similar results regarding the effects of particle size on mechanical properties of WPCs from HDPE and recycled wood particles. In addition, the results of this study comply with the results documented by Rahman et al. [3] for sawdust and PET composites at different mixing ratios. However, the results of MOR deviated from the results reported by Ayrilmis and Jarusombuti [8] that the MOR of the WPCs increased with the increasing wood particle content from 40 to $50 \%$ and decreased for further increase of the wood particle content. Moreover, MOR of the composites except for A-60 and A-70 fulfilled the required standard of ANSI [17] for high-density particleboard $\left(16.5 \mathrm{~N} / \mathrm{mm}^{2}\right)$. Nevertheless, all the formulations met the required standard for MOR of medium density particleboard $\left(11 \mathrm{~N} / \mathrm{mm}^{2}\right)$ [17]. Thus, MOR of the WPCs varied considerably based on particle sizes and mixing ratios and reached the required standard.

\section{Decay resistance}

The weight loss of both A- and B-type WPCs subjected to soil block test was depicted in Fig. 7. Statistical analysis with two-way ANOVA followed by LSD showed that the 
weight loss of the WPCs was significantly affected by the particle sizes $\left(F_{1,40}=249.499, P<0.05\right)$ and mixing ratios $\left(F_{3,40}=3.312 \times 10^{3}, P<0.05\right)$. Moreover, it was observed that the weight loss of WPCs increased with the increasing wood particle content in the formulation from 40 to $70 \%$. Moreover, B-type WPCs containing large particles showed a lower weight loss compared to the A-type WPCs containing small particles. The variations in weight loss might be due to decay resistance aptitude of PET as well as different mixing ratios in the WPC formulations. Besides, particle size might also be affected the weight loss of the WPC panels. However, WPCs fabricated from higher wood particle content showed higher weight loss, because wood is biodegradable in nature. Uniform distribution of thermoplastic matrix and better encapsulation of large wood particles through matrix might affected the weight loss of the WPCs in this study. Mankowski and Morrel [22] found similar results for pine/polyethylene composites. Pine/polyethylene composites with $70 \%$ particle content showed considerably higher weight loss than composites made of 50\% particle content. Moreover, the results of this study also complied with the results reported by Verhey et al. [23] and Ebe and Sekino [13], because WPCs with higher particle contents are more susceptible to natural decay. Moreover, Kartal et al. [24] described similar results that the composites having large particles showed a lower weight loss than the smaller particle sized specimens. However, wood plastic ratio may have a greater effect on decay resistance of WPCs rather than wood particle size as reported by Pendleton et al. [25], which also support this study. Therefore, the results suggested that PET content in the WPC formulations plays the inhibiting role against natural decay exposed to controlled environmental conditions in this study.

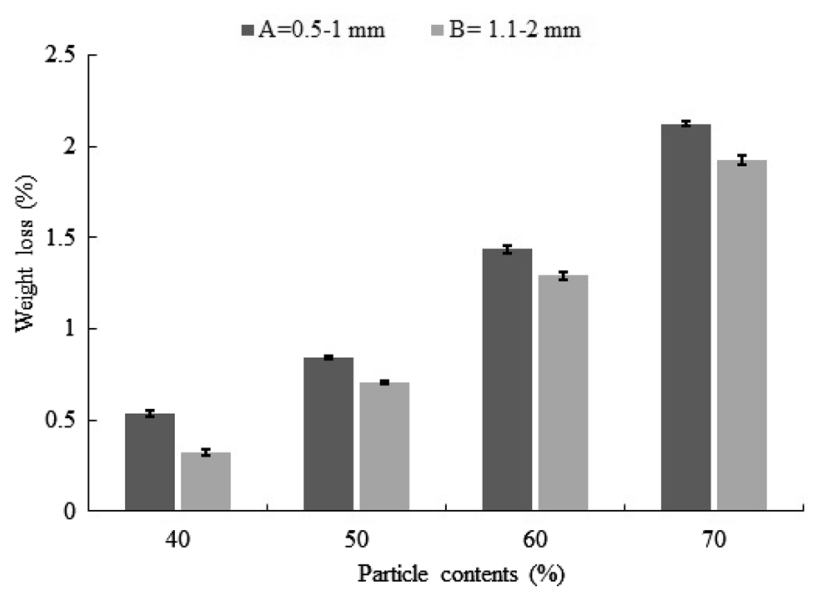

Fig. 7 Effects of particle size and mixing ratio on weight loss of Aand B-type WPCs. In figure, error bars indicate the standard error of the mean

\section{Conclusion}

The physical and mechanical properties as well as the decay resistance of the WPCs are significantly depend on the particle sizes and mixing ratios used in the formulations. Furthermore, B-type WPCs showed relatively lower density, WA, and TS with an exception of slightly higher moisture content than A-type composites. In the meantime, B-type WPCs made with 50\% larger particles show elevated bending strength compared to all the WPCs. Besides, WA and TS of both types of WPCs substantially increased with the increase of immersion temperature from 25 to $75^{\circ} \mathrm{C}$. Furthermore, like physical and mechanical properties, decay resistance of composites varied with the particle sizes and particle content. Consequently, fabrication of WPCs with large particles (particularly 50\% large particles that showed promising results) is technically feasible. However, the results also suggested that density reduction and/or improvement of MOE are inevitable. Therefore, it would be better to fabricate WPCs with agricultural waste fiber instead of wood particle to reduce density and coupling agent to enhance wood plastic interaction by reducing the melting temperature of PET and, thus, recommended for further research.

Acknowledgements The authors would like to thank Akij Particle Board Mills Ltd. Manikganj, Bangladesh for providing the support to evaluate the mechanical properties of the WPCs.

\section{Compliance with ethical standards}

Conflict of interest The authors have declared that they have no conflict of interest.

\section{References}

1. Clemons C (2002) Wood-plastic composites in the United States: the interfacing of two industries. For Prod J 52(6):10-18

2. Najafi SK, Tajvidi M, Hamidina E (2007) Effect of temperature, plastic type and virginity on the water uptake of sawdust/plastic composites. Holz Roh Werkst 65(5):377-382

3. Rahman KS, Islam MN, Rahman MM, Hannan MO, Dungani R, Khalil HA (2013) Flat-pressed wood plastic composites from sawdust and recycled polyethylene terephthalate (PET): physical and mechanical properties. SpringerPlus 2:629

4. Chaharmahali M, Tajvidi M, Najafi SK (2008) Mechanical properties of wood plastic composite panels made from waste fiberboard and particleboard. Polym Compos 29(6):606-610

5. Ayrilmis N, Benthien JT, Thoemen H, White RH (2012) Effects of fire retardants on physical, mechanical, and fire properties of flat-pressed WPCs. Eur J Wood Prod 70(1-3):215-224

6. Chen HC, Chen TY, Hsu CH (2006) Effects of wood particle size and mixing ratios of HDPE on the properties of the composites. Holz Roh Werkst 64(3):172-177

7. Benthien J, Thoemen H, Weißmann V (2009) Flat-pressed WPC: effects of raw materials and process parameters on the physical and mechanical board properties. In: Carus M (ed) 
Third German WPC-Congress, 2-3 December 2009. Maritim Hotel, Köln, p 19

8. Ayrilmis N, Jarusombuti S (2011) Flat-pressed wood plastic composite as an alternative to conventional wood-based panels. J Compos Mater 45(1):103-112

9. Benthien JT, Thoemen H (2012) Effects of raw materials and process parameters on the physical and mechanical properties of flat pressed WPC panels. Compos Part A Appl Sci Manuf 43(4):570-576

10. Ayrilmis N, Jarusombuti S, Fueangvivat V, Bauchongkol P (2011) Effect of thermal-treatment of wood fibres on properties of flat-pressed wood plastic composites. Polym Degrad Stab 96(5):818-822

11. Jarusombuti S, Ayrilmis N (2011) Surface characteristics and overlaying properties of flat-pressed wood plastic composites. Eur J Wood Prod 69(3):375-382

12. Fang L, Xiong X, Wang X, Chen H, Mo X (2017) Effects of surface modification methods on mechanical and interfacial properties of high-density polyethylene-bonded wood veneer composites. J Wood Sci 63(1):65-73

13. Ebe K, Sekino N (2015) Surface deterioration of wood plastic composites under outdoor exposure. J Wood Sci 61(2):143-150

14. ASTM E11-17 (2017) Standard specification for woven wire test sieve cloth and test sieves. ASTM International, West Conshohocken

15. ASTM D 1037 (1999) Standard test methods for evaluating properties of wood-based fiber and particle panel materials static tests of timbers. ASTM, Philadelphia

16. BS EN ISO 846 (1997) Plastic-evaluation of the action of microorganisms. International Organization for Standardization, Geneva
17. ANSI A208 (1999) American National Standard: particleboard. CPA, Gaithersburg, $p 11$

18. Adhikary KB, Pang S, Staiger MP (2008) Dimensional stability and mechanical behaviour of wood-plastic composites based on recycled and virgin high-density polyethylene (HDPE). Compos B Eng 39(5):807-815

19. Hidayat HERP., Keijsers ERP, Prijanto U, van Dam JEG, Heeres HJ (2014) Preparation and properties of binderless boards from Jatropha curcas L. seed cake. Ind Crops Prod 52:245-254

20. Bledzki AK, Faruk O, Huque M (2002) Physico-mechanical studies of wood fiber reinforced composites. Polym Plast Technol Eng 41(3):435-451

21. Shibata M, Takachiyo K, Ozawa K, Yosomiya R, Takeishi $\mathrm{H}$ (2002) Biodegradable polyester composites reinforced with short abaca fiber. J Appl Polym Sci 85(1):129-138

22. Mankowski M, Morrell JJ (2000) Patterns of fungal attack in wood-plastic composites following exposure in a soil block test. Wood Fiber Sci 32:340-345

23. Verhey S, Laks P, Richter D (2001) Laboratory decay resistance of woodfiber/thermoplastic composites. For Prod J 51(9):44-49

24. Kartal SN, Aysal S, Terzi E, Yilgör N, Yoshimura T, Tsunoda K (2013) Wood and bamboo-PP composites: fungal and termite resistance, water absorption, and FT-IR analyses. BioResources $8(1): 1222-1244$

25. Pendleton DE, Hoffard TA, Adcock T, Woodward B, Wolcott MP (2002) Durability of an extruded HDPE/wood composite. For Prod J 52(6):21-27 